\title{
ANÁLISE DE DIFERENTES VISCOSIDADES A PARTIR DA APLICAÇÃO DO AQUECIMENTO GERAL INDIRETO COMO MÉTODO DE RECUPERAÇÃO EM RESERVATÓRIOS PETROLÍFEROS
}

\author{
E. J. R. MEDEIROS ${ }^{1,2}$; R. N. MEDEIROS JÚNIOR ${ }^{1}$; J. S. ARAÚJO ${ }^{2}$; J. L. M. BARILLAS ${ }^{2}$; T. V. DUTRA JUNIOR ${ }^{2}$; W. \\ MATA $^{2}$ \\ 'Instituto Federal de Educação, Ciência e Tecnologia do Rio Grande do Norte \\ ${ }^{2}$ Departamento de Engenharia de Petróleo - Universidade Federal do Rio Grande do Norte \\ elthon.medeiros@ifrn.edu.br - nonato.junior@ifrn.edu.br - janusasoares@yahoo.com.br - jennys@eq.ufrn.br \\ - tarcilio@eq.ufrn.br -wilson@ct.ufrn.br
}

Artigo submetido em outubro/2011 e aceito em novembro/2011

\section{RESUMO}

Cada barril de petróleo é relevante e até os campos produtores de difícil acesso têm importância. $O$ petróleo viscoso e os baixos níveis de pressão nos reservatórios rasos dificultam a recuperação. O principal método de recuperação aplicado a esse tipo de petróleo é a injeção de vapor. O Aquecimento Geral Indireto - AGI (Blanket Heating) é uma técnica que utiliza a injeção de vapor através de canalizações horizontais. O fluido aquecido funciona como um trocador de calor, transferindo indiretamente o calor do vapor ao óleo, reduzindo a sua viscosidade. Para testar esse método e compará-lo ao tradicional processo de injeção contínua de vapor foi utilizado o simulador comercial STARS da
CMG. Estudou-se a eficiência do método em relação à variação nos parâmetros de reservatório. Os resultados mostraram que a recuperação pode ser maximizada proporcionalmente ao aumento no número de canalizações e da sua temperatura. A produção acumulada de óleo diminuiu quando as canalizações foram afastadas entre si, ou dos poços produtores. 0 AGI não produziu emissões consideráveis de vapor à superfície, confirmando a redução na água produzida. Houve diferença significativa entre as recuperações primárias de modelos com viscosidades distintas, quando aplicado nesses mesmos modelos o processo AGI, sobretudo entre óleos de 300 e 10000 cP.

PALAVRAS-CHAVE: óleo pesado, reservatórios rasos, aquecimento geral indireto, simulação

computacional.

\section{ANALYSIS OF DIFFERENT VISCOSITY THROUGH APPLICATION OF BLANKET HEATING METHOD OF RECOVERY IN PETROLEUM RESERVOIRS}

\begin{abstract}
Each barrel of oil is relevant and even the producers fields with difficult access has importance. The oil viscosity and the low pressure in the shallows reservoir, hinder the recovery. The main recovery method applied for this kind of oil is the steam injection. Blanket Heating is a technique that uses the steam injection through horizontal conduits. The heated fluid functions as a heat exchanger, indirectly transferring heat from steam to oil, reducing its viscosity. To test this method and comparing it with the traditional process of continuous steam injection, the commercial simulator STARS from CMG has used. It was studied the efficiency of the method in relation to changes in reservoir parameters.
\end{abstract}

The results showed that the recovery can be maximized in proportion to the increase in the conduits numbers and its temperature. Cumulative oil decreased when the conduits were moved away from each other, or from the producers wells. The blanket heating does not produce significant emissions of steam to the surface area, confirming the reduction in the produced water. There were significant differences between the primary recovery of models with different viscosities, when applied in these models the AGI process, especially between oil 300 and 10000 cP. 
KEY-WORDS: heavy oil, shallow reservoirs, blanket heating, computer simulation. 


\section{ANÁLISE DE DIFERENTES VISCOSIDADES A PARTIR DA APLICAÇÃO DO AQUECIMENTO GERAL INDIRETO COMO MÉTODO DE RECUPERAÇÃO EM RESERVATÓRIOS PETROLÍFEROS}

\section{INTRODUÇÃO}

$\mathrm{Na}$ engenharia de reservatórios de petróleo, as análises envolvendo etapas de exploração e produções necessitavam da observação das variáveis geológicas (tipo de formação geológica, porosidade, permeabilidade, etc.) relevantes e das condições de mercado, a tal ponto, que a existência abundante de boas jazidas afastava a necessidade da utilização de métodos de recuperação avançados e mais abrangentes. Todavia, essa circunstância alterou-se com a depleção de campos produtivos a baixos custos, da globalização dos negócios e do envolvimento de vários outros agentes, tornando o processo de tomada de decisão bastante complexo, e nem sempre de fácil solução devido ao aumento do preço de petróleo que pode tornar rentáveis processos que anteriormente não eram.

A maior parte das reservas de petróleo do mundo corresponde a hidrocarbonetos viscosos e pesados. Segundo Alboudwarej (2006) as estimativas do total de reservas de petróleo no mundo oscilam entre 9 a 13 trilhões de barris, incluindo óleos pesados, ultra pesados e o betume que, somados representam cerca de $70 \%$ dos recursos petrolíferos (Mothé e Silva Jr., 2008).

Segundo Medeiros (2008) reservatórios de óleo com profundidade inferior a 300 m contêm, geralmente, óleo pesado (viscoso). Em reservatórios mais profundos, a pressão, na maioria dos casos, pode ser suficiente para a elevação natural dos fluidos do reservatório. Em reservatórios rasos, a pressão pode não ser suficiente para fornecer uma produção economicamente viável, portanto pode ser necessária a aplicação de um dos métodos de recuperação para aumentar o fluxo.

O petróleo bruto viscoso combinado com os baixos níveis de pressão no reservatório pode determinar dificuldades para recuperação do óleo nos reservatórios rasos, sendo assim necessária a utilização de métodos que envolvam injeção indireta de fluidos devido às formações geológicas inconsolidadas presentes, e métodos térmicos para redução da viscosidade. Uma possível solução para esse problema seria o emprego dos métodos de aquecimento indireto (Medeiros, 2008 apud DunnNorman et al., 2002).

Diversos esquemas de recuperação suplementar para os reservatórios rasos foram analisados pela indústria petrolífera, incluindo a injeção de vapor, a injeção de $\mathrm{CO}_{2}$, a combustão in situ, a recuperação microbiológica, o aquecimento elétrico direto e a estimulação com explosivos. Em teoria, os mais bem sucedidos envolvem aquecimento geral indireto, capaz de recuperar o óleo pelos mecanismos tradicionais de redução da viscosidade e drenagem gravitacional.

O Aquecimento Geral Indireto (AGI) é um método de recuperação que visa superar as dificuldades de aplicação da injeção de vapor em reservatórios rasos, a partir da condução do calor do vapor ao óleo, através de canalizações (sem contato entre o vapor e o óleo). Neste processo, o vapor produzido em um gerador convencional flui em canalizações horizontais, para fornecer calor através de toda a formação. $O$ vapor contido nas canalizações evita o inconveniente de inserir grandes quantidades de fluidos diretamente no reservatório, além de facilitar a manutenção da temperatura por meio do controle de vapor injetado e da pressão nas tubulações. As canalizações funcionam como trocadores de calor. 


\section{ASPECTOS TEÓRICOS}

\section{- Descrição do Método AGI}

O processo Aquecimento Geral Indireto (AGI), descrito por Osterloh e Jones (2001), é, segundo Dunn-Norman et al. (2002) o único método publicado que inclui canalizações horizontais aplicadas em reservatórios rasos e ultra rasos.

No processo AGI, o vapor produzido em um gerador convencional flui através de canalizações horizontais, para fornecer calor através de toda a formação (Figura 1). O vapor contido nas canalizações evitaria o inconveniente de inserir grandes quantidades de fluido diretamente no reservatório, além de facilitar a manutenção da temperatura através do controle de vapor injetado e da pressão nas tubulações.

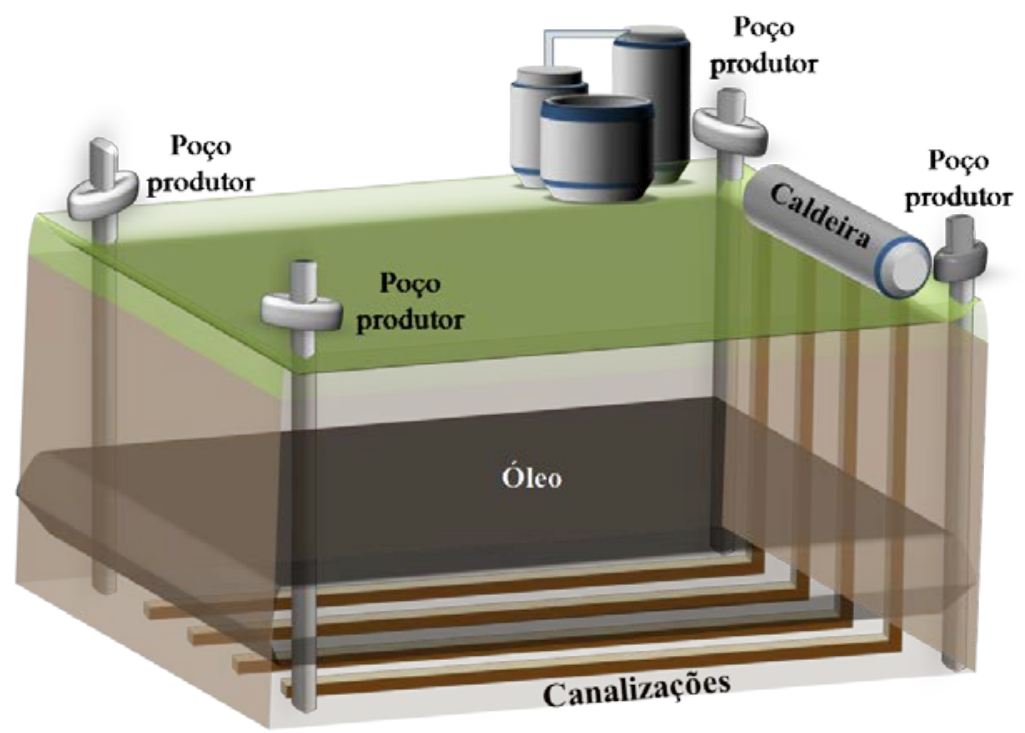

Figura 1 - Esquema representativo do método AGI

Poços de produção são perfurados no reservatório para estabelecer o fluxo de fluidos, sendo também utilizados poços de injeção para manutenção da pressão. Quando a pressão no reservatório atinge um limite abaixo do desejável, pode-se injetar-se um fluido (água, vapor, nitrogênio) através dos poços de injeção. Quando a pressão mantém-se elevada, líquidos ou gás são produzidos (Osterloh e Jones, 2001).

As canalizações devem voltar à superfície para que o vapor seja reaquecido nas caldeiras. Uma alternativa seria o vapor voltar internamente pelas canalizações. Nesta configuração, um compartimento externo, anular, é utilizado para conduzir o vapor de alta qualidade até a extremidade final da canalização, transmitindo calor por condução para a formação, e um tubo concêntrico isolado, denominado ICCT (Insulated Concentric Coiled Tubing), localizado internamente ao anular, é usado para que esse fluido retorne às caldeiras.

Nzekwu e Pelensky (1997) patentearam este conceito de uso do mesmo poço para injetar 
vapor, bem como para produzir fluidos e verificaram que a câmara de vapor cresce verticalmente em direção ao topo do reservatório sob a influência do empuxo gravitacional, cresce lateralmente pela condução de calor nas extremidades da câmara e pelo fluxo convectivo devido à alta pressão da injeção de vapor e cresce longitudinalmente ao longo do poço horizontal, através do aumento da pressão causada pela injeção de vapor na ponta do poço; e pela pequena queda de pressão dentro do anular, como resultado do escoamento entre o tubo injetor e o liner rasgado (Moreira e Trevisan, 2007). A Figura 2 apresenta o tubo concêntrico ICCT.

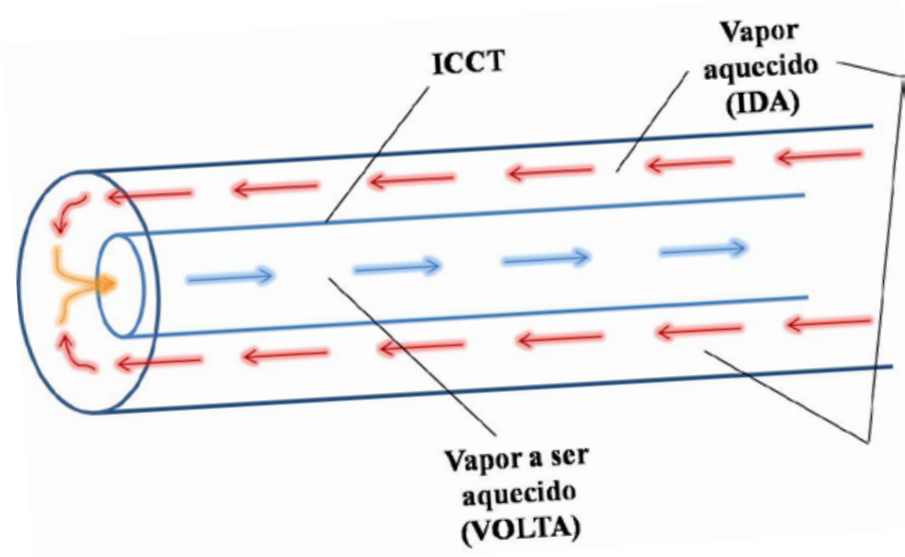

Figura 2 - Tubo concêntrico ICCT

\section{- Mecanismos do processo AGI}

O processo envolve a condução de calor - do vapor ao óleo, através das canalizações. Nesse sentido, a alternativa ideal para o material das canalizações seria aquele capaz de melhorar a condução de calor, sendo resistente o bastante para suportar a pressão e outros fatores. Por atender a essas expectativas, o aço pode ser adotado para a técnica. Uma vez transmitido ao óleo, o calor se difunde pelos hidrocarbonetos por convecção e também por condução (em menor escala). O óleo em contato com as canalizações sofre redução na densidade e tende a subir, mobilizando o óleo disposto superiormente, induzindo o fluxo vertical, e facilitando a transmissão de energia térmica e também a produção nos poços. As canalizações são posicionadas abaixo do óleo, para condicionar o processo de convecção. $O$ processo é privilegiado também pela elevada permeabilidade (vertical e horizontal) dos reservatórios rasos.

Além da transferência de calor, o sucesso do processo se deve à existência de processos adicionais de vaporização/condensação in situ. O vapor que se forma em torno da canalização eleva-se passando através dos sedimentos, e acelerando a transferência de calor para zonas de temperatura menor. Quando o vapor se condensa finalmente, o líquido será drenado para baixo, preenchendo a área quente em torno da canalização, onde será vaporizado outra vez (Figura 3) (Osterloh e Jones, 2001). 


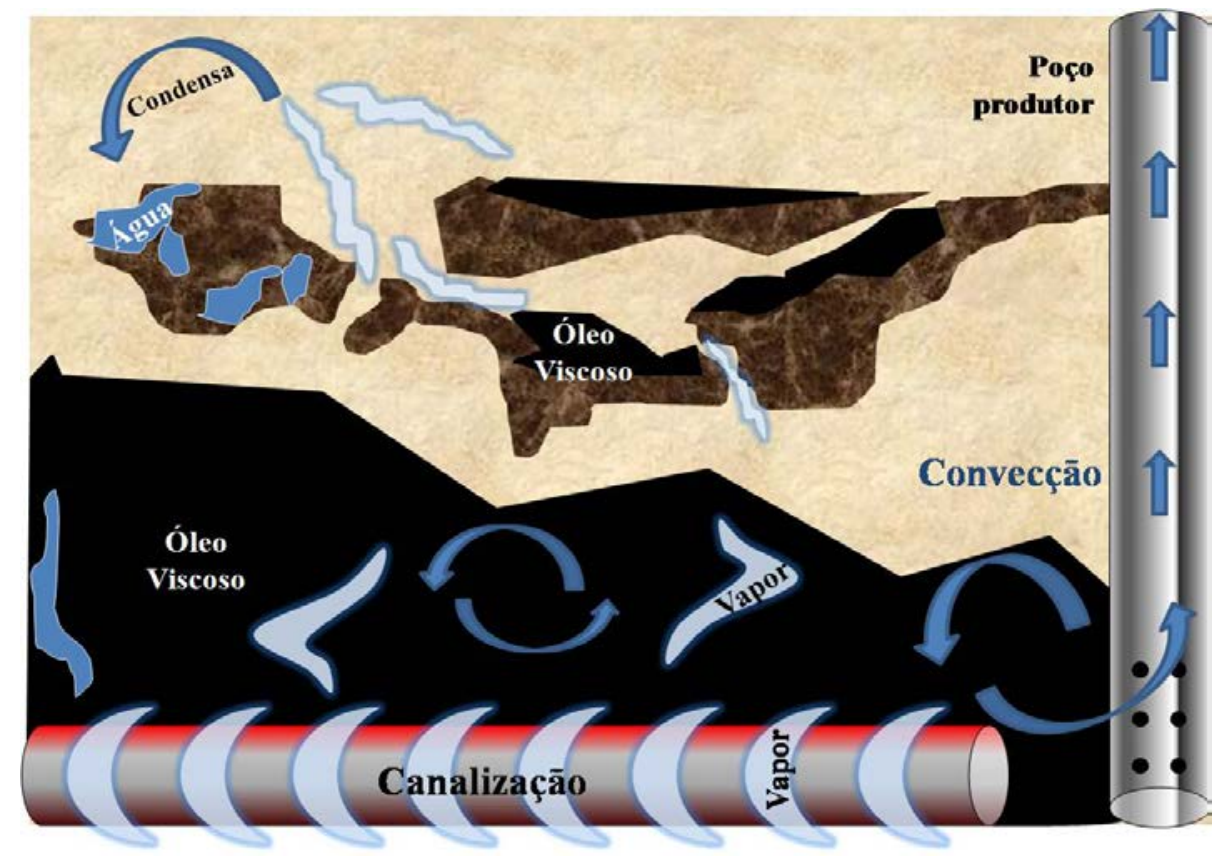

Figura 3 - Mecanismos do processo AGI

\section{METODOLOGIA}

O processo foi realizado através de um simulador comercial, STARS (Steam, Thermal, and Advanced Processes Reservoir Simulator) - versão 2007, um simulador numérico trifásico de múltiplos componentes da CMG (Computer Modelling Group) desenvolvido com a finalidade de simular recuperações térmicas de óleo.

A configuração dos poços obedece ao padrão de malha five-spot invertido, que é constituído de um poço injetor no centro da malha e quatro produtores nos vértices. Tendo em vista a simetria de resultados (homogeneidade) e o tempo de simulação, a malha foi constituída de $1 / 4$ de five-spot, ou seja, $1 / 4$ de produtor e $1 / 4$ de injetor.

O modelo estudado é tridimensional e representa um reservatório semissintético, com características da Bacia Potiguar em um modelo homogêneo, em forma de paralelepípedo de dimensões $60 \mathrm{~m} \times 60 \mathrm{~m} \times 32 \mathrm{~m}$, como apresentado na Figura 4. Possui canalizações horizontais de aço, cujo comprimento equivale à largura completa do campo, que são aquecidas, de modo a simular que seu interior contém vapor d'água. O reservatório é constituído por uma zona de óleo e capa de gás.

O sistema selecionado utiliza coordenadas cartesianas com nas direções dos vetores unitários " $i$ ", " $j$ " e " $k$ ", totalizando 4440 blocos, que constituem a malha de simulação (Figura 5). 


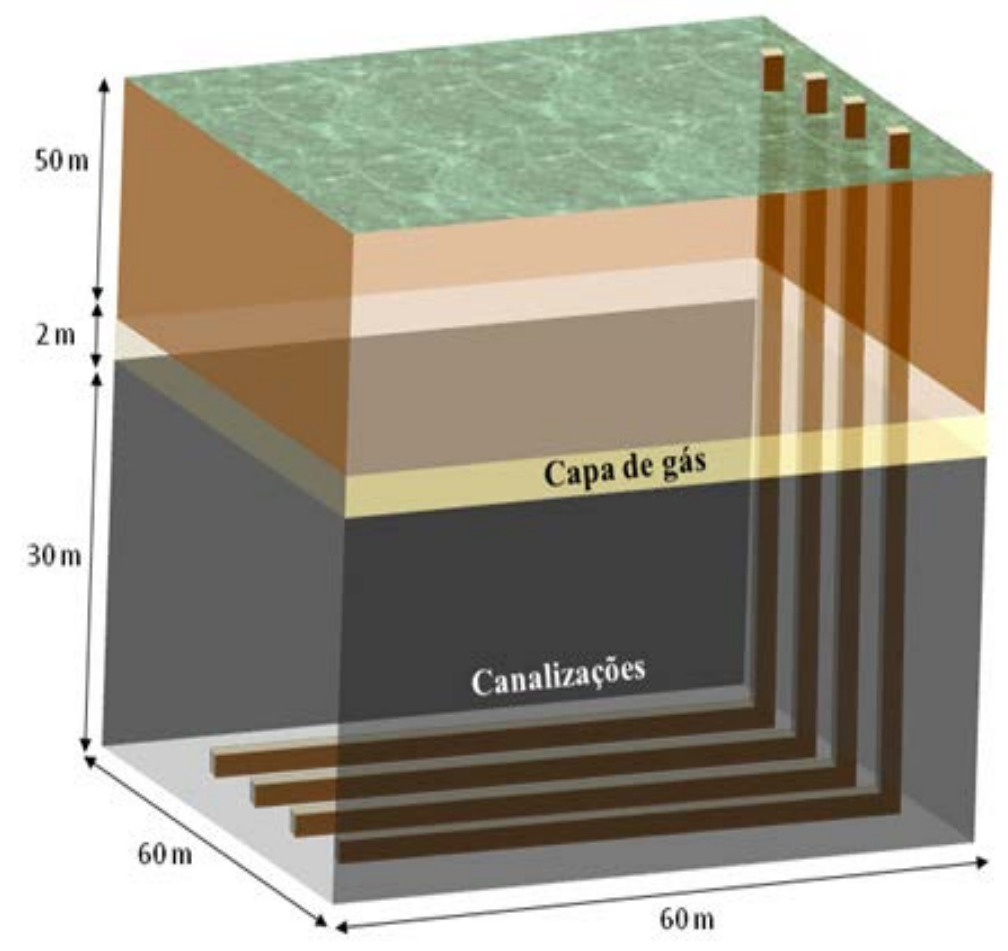

Figura 4 - Representação do sistema AGI

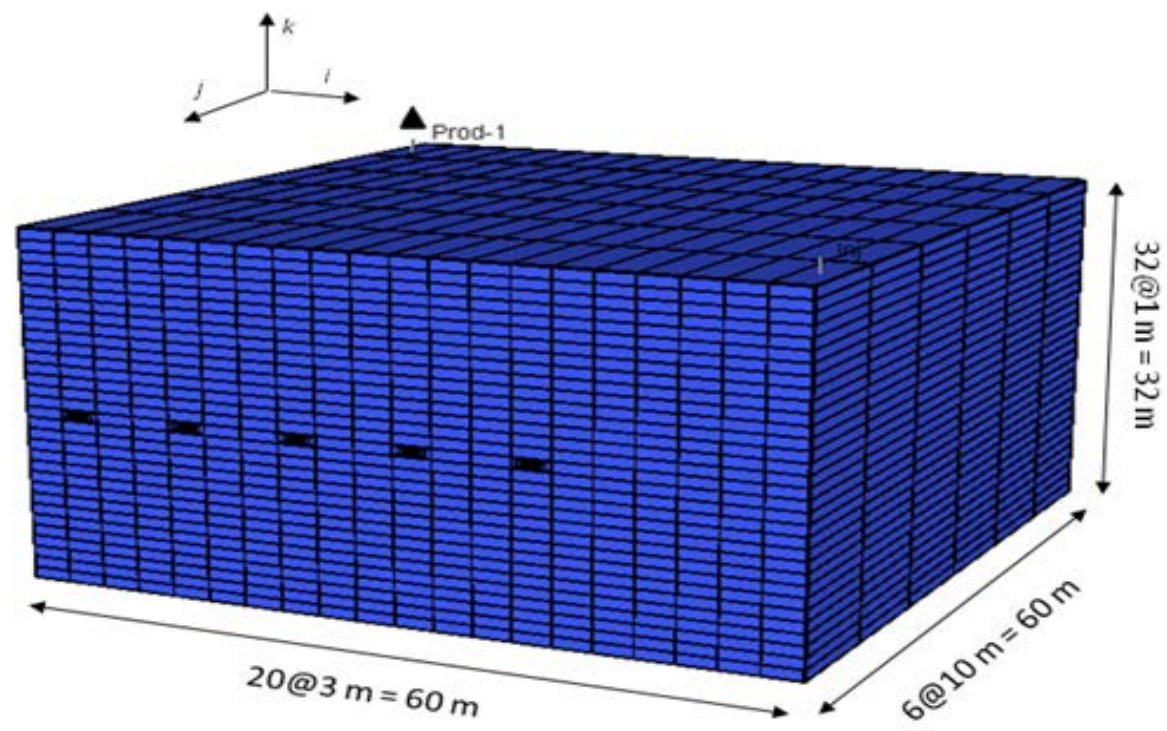

Figura 5 - Modelo Base 3D

As canalizações foram dispostas ao longo da direção " $j$ ", e correspondem às colunas horizontais de blocos com refinamento radial, e diâmetro igual a $5 \mathrm{~cm}$. Apenas os blocos representativos das canalizações foram aquecidos, em diversas temperaturas, com intuito de avaliar a capacidade dessa configuração para transferir calor ao reservatório em diferentes situações (Figura 6). 


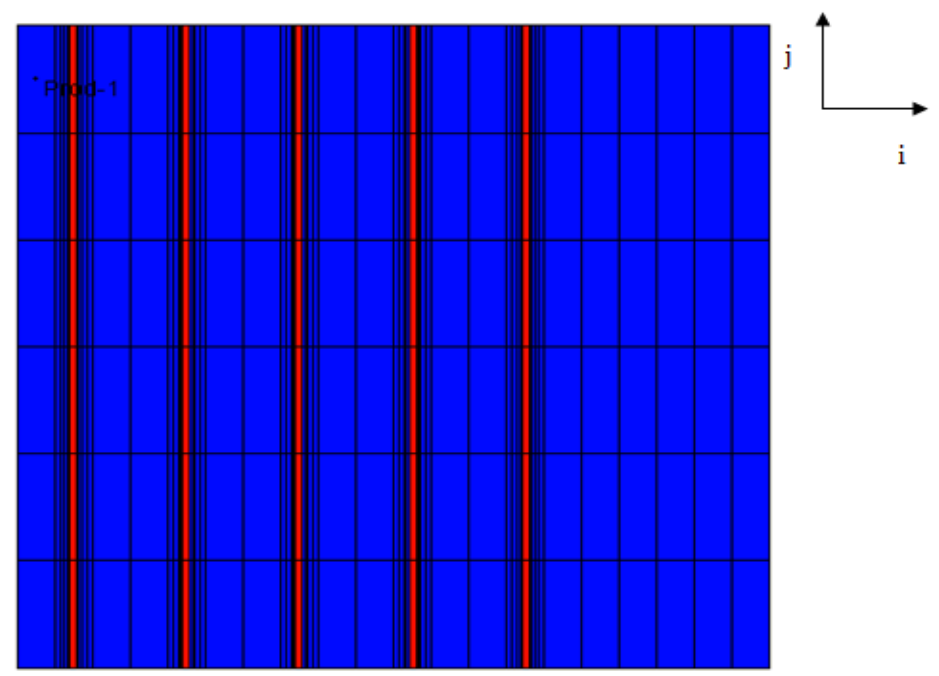

Figura 6 - Planta das canalizações

\section{CONDIÇÕES INICIAIS}

Nesta seção são definidas as condições iniciais do reservatório (Tabela 1), ou seja, as características apresentadas antes de qualquer operação a ser efetuada. As propriedades foram baseadas em dados de reservatórios reais e dados disponíveis na literatura.

Tabela 1: Propriedades do Reservatório e da Rocha

\begin{tabular}{|c|c|c|c|}
\hline \multicolumn{2}{|l|}{ Propriedades do Reservatório } & \multicolumn{2}{|l|}{ Propriedades da Rocha } \\
\hline Capa de gás - DGOC (m) & 2 & $\begin{array}{l}\text { Compressibilidade Efetiva da Rocha } \\
(1 / \mathrm{Pa})\end{array}$ & $4,4 \cdot 10^{-7}$ \\
\hline Comprimento - i (m) & 60 & $\begin{array}{l}\text { Condutividade Térmica da Rocha } \\
\qquad\left(\mathrm{J} / \mathrm{m} . \mathrm{s} .{ }^{\circ} \mathrm{C}\right)\end{array}$ & 1,73 \\
\hline Largura - j (m) & 60 & $\begin{array}{l}\text { Condutividade Térmica da Água } \\
\qquad\left(\mathrm{J} / \mathrm{m} . \mathrm{s}^{\circ} \mathrm{C}\right)\end{array}$ & 0,61 \\
\hline Espessura - k (m) & 32 & $\begin{array}{l}\text { Condutividade Térmica do Óleo } \\
\qquad\left(\mathrm{J} / \mathrm{m} . \mathrm{s}^{\circ} \mathrm{C}\right)\end{array}$ & 0,13 \\
\hline Profundidade do reservatório (m) & 50 & $\begin{array}{l}\text { Condutividade Térmica do Gás } \\
\left(\mathrm{J} / \mathrm{m} . \mathrm{s}^{\circ} \mathrm{C}\right)\end{array}$ & 0,04 \\
\hline Saturação inicial de água (\%) & 30 & $\begin{array}{l}\text { Permeabilidade Horizontal - Kh } \\
\qquad(\mathrm{mD})\end{array}$ & 1000 \\
\hline Saturação inicial de óleo (\%) & 70 & Permeabilidade Vertical - Kv (mD) & 100 \\
\hline Temperatura inicial $\left({ }^{\circ} \mathrm{C}\right)$ & 37,8 & \multirow{2}{*}{ Porosidade - $\phi(\%)$} & \multirow{2}{*}{28} \\
\hline volume "in place" ( $\left.\mathrm{m}^{3} \mathrm{std}\right)$ & 21509 & & \\
\hline
\end{tabular}




\title{
DESCRIÇÃO DO ESTUDO
}

Foram realizadas simulações iniciais para análise do comportamento da injeção de vapor através de canalizações (AGI). Com isso, foi possível identificar os principais fatores, bem como, a melhor configuração para refinamento, ou seja, o modelo mais próximo da realidade (Medeiros, 2008).

De acordo com o estudo dos parâmetros de reservatório descrita em Medeiros (2008), alcançada a partir do planejamento experimental e aplicações iniciais, foram escolhidos três modelos de reservatórios ("ótimo", "intermediário" e "péssimo") para analisar a aplicabilidade do AGI nos modelos selecionados. Os modelos apontados pelos resultados viabilizaram um novo estudo com análises de componentes isolados ou simulações de parâmetros já pesquisados, em mais níveis, para determinar se as mudanças operacionais escolhidas podem ser mais atrativas.

Dessa forma foi realizada uma análise comparativa da aplicação de um modelo otimizado em óleos de viscosidades 300, 1000, 3000, 5000 e 10000 cP.

Esse estudo visa obter a abrangência do processo Aquecimento Geral Indireto (AGI) para reservatórios com óleo pesado e ultra pesado. Os dados para a curva de viscosidade foram obtidos pela projeção das curvas de viscosidade (Barillas, 2005). A curva de viscosidade utilizada foi a de 1000 cP para uma temperatura no reservatório de $37,8^{\circ} \mathrm{C}\left(100{ }^{\circ} \mathrm{F}\right)$. A equação (1) exibe uma relação entre a temperatura e a viscosidade (Dutra Jr., 1987).

$\log (\log (\mu+1,05))=a \log (T)+b$ equação (1)

onde:

\author{
T: Temperatura (R) \\ $\mu$ : Viscosidade (cP)
}

$$
\begin{aligned}
& a=-3,62, b=10,343 \text { para } 300 \mathrm{cP} @ 37,8{ }^{\circ} \mathrm{C} \\
& a=-3,62, b=10,426 \text { para } 1000 \mathrm{cP} @ 37,8{ }^{\circ} \mathrm{C} \\
& a=-3,62, b=10,490 \text { para } 3000 \mathrm{cP} @ 37,8{ }^{\circ} \mathrm{C} \\
& a=-3,62, b=10,516 \text { para } 5000 \mathrm{cP} @ 37,8{ }^{\circ} \mathrm{C} \\
& a=-3,62, b=10,550 \text { para } 10000 \mathrm{cP} @ 37,8{ }^{\circ} \mathrm{C}
\end{aligned}
$$

A Figura 7 apresenta as retas paralelas para obtenção das curvas de viscosidade, enquanto a Figura 8 representa as próprias curvas. 

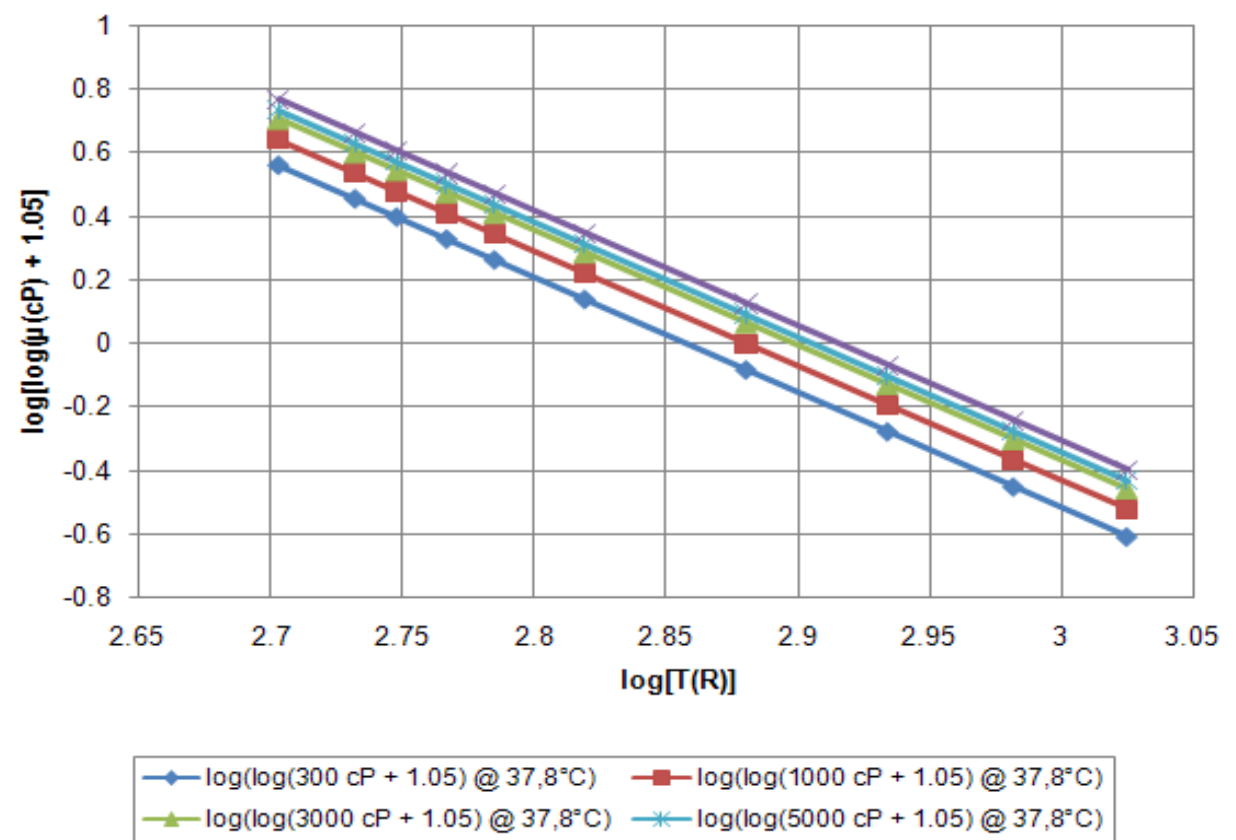

Figura 7 - Retas paralelas da equação (1) para projeção das curvas de viscosidades

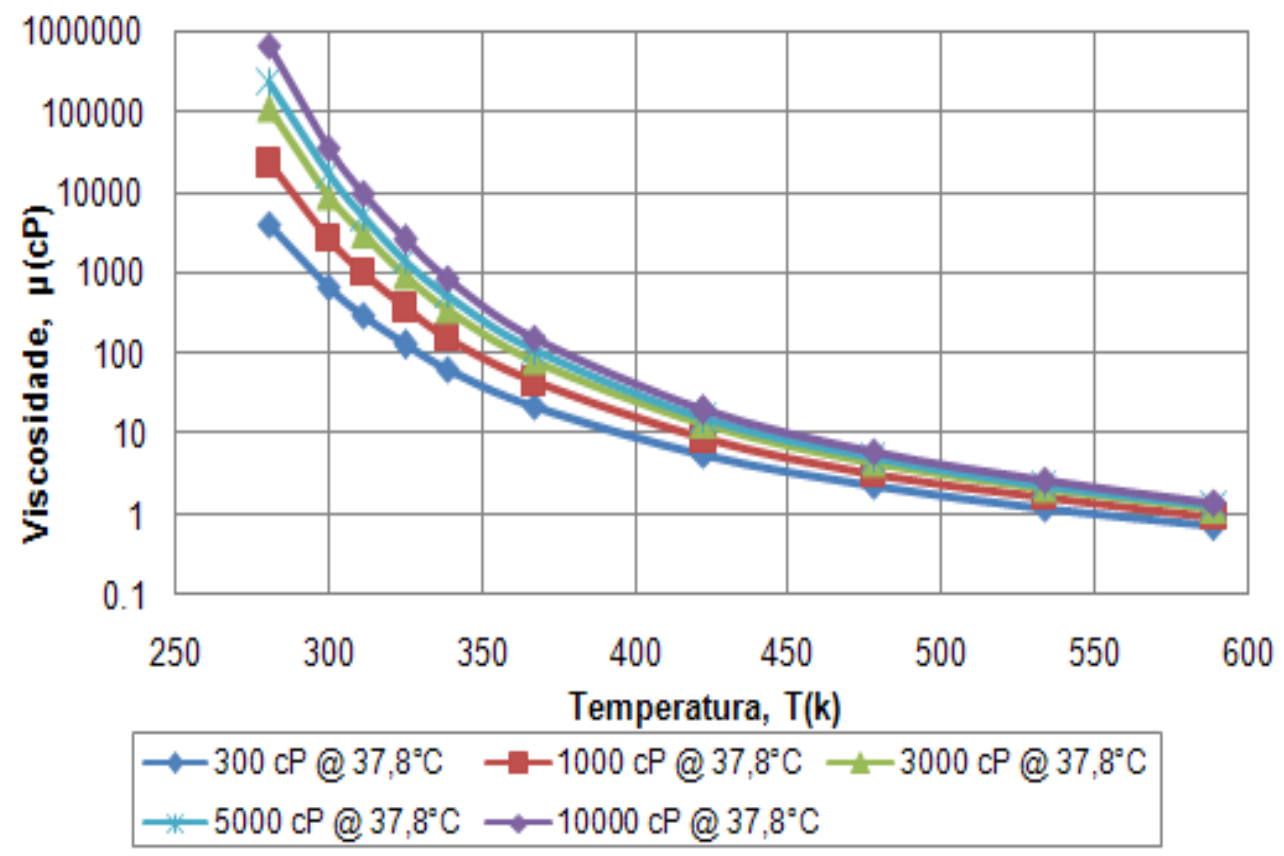

Figura 8 - Curvas de viscosidade do óleo 


\section{RESULTADOS E DISCUSSÃO}

Os resultados obtidos a partir do processo $A G I$, em reservatórios rasos, com diferentes viscosidades, serão apresentados nesta seção bem como as suas respectivas discussões.

Realizou-se um estudo com os principais parâmetros de reservatório, visando à escolha de três modelos, ou seja, três tipos diferentes de reservatório (" $A$ ", " $B$ " e " $C$ "), para desenvolver uma maneira eficiente de trabalho operacional do processo AGI através do fator de recuperação para cada um desses reservatórios.

Na fase de simulação dos parâmetros de reservatório, as condições operacionais do modelo base, assim como as características do reservatório que não interessavam para a análise foram fixadas.

A Tabela 2 mostra um resumo por nível de cada reservatório escolhido para as análises do estudo. Esses parâmetros foram estudados por Medeiros (2008) segundo a influência nos Diagramas de Pareto e nas máximas respostas do sistema através das Superfícies de Repostas e Curvas de Nível.

Tabela 2 - Características dos reservatórios analisados

\begin{tabular}{|c|c|c|c|c|}
\hline Cenário & “A" & "B" & “C” & BASE \\
\hline FR & $69,95 \%$ & $45,85 \%$ & $21,88 \%$ & $29,98 \%$ \\
\hline$\mu(c P)$ & $\begin{array}{c}1000 \\
(-1)\end{array}$ & $\begin{array}{r}3000 \\
(+1)\end{array}$ & $\begin{array}{r}3000 \\
(+1)\end{array}$ & 1000 \\
\hline C. Gás (m) & $\begin{array}{c}2 \\
(-1)\end{array}$ & $\begin{array}{c}4 \\
(+1)\end{array}$ & $\begin{array}{c}4 \\
(+1)\end{array}$ & 2 \\
\hline $\mathrm{Kh}(\mathrm{mD})$ & $\begin{array}{r}3000 \\
(+1)\end{array}$ & $\begin{array}{r}3000 \\
(+1)\end{array}$ & $\begin{array}{c}1000 \\
(-1)\end{array}$ & 1000 \\
\hline Kv/Kh & $\begin{array}{l}0,2 \\
(+1)\end{array}$ & $\begin{array}{r}0,05 \\
(-1)\end{array}$ & $\begin{array}{r}0,05 \\
(-1)\end{array}$ & 0,1 \\
\hline Profundidade (m) & $\begin{array}{l}150 \\
(+1)\end{array}$ & $\begin{array}{c}100 \\
(0)\end{array}$ & $\begin{array}{c}50 \\
(-1)\end{array}$ & 50 \\
\hline
\end{tabular}

- " $A$ " - configuração que obteve maior fator de recuperação;

- "B" - configuração que obteve fator de recuperação intermediário;

- " "C" - configuração que obteve menor fator de recuperação.

- ANÁLISE COMPARATIVA DA APLICAÇÃO DO MODELO OTIMIZADO EM ÓLEOS DE VISCOSIDADES 300, 1000, 3000, 5000 e 10000 cP 
Em Medeiros (2008) verificou-se que o método AGI é adequado para óleos de viscosidade 1000 e 3000 cP, faltando apenas analisar essa adequação para óleos ainda mais pesados, como também para óleos mais leves.

\section{- COMPARAÇÃO DE VISCOSIDADE PARA O RESERVATÓRIO “A”}

A Figura 9 mostra a situação da viscosidade do óleo após 3 anos de aquecimento (reservatório "A"). Observa-se uma grande redução da viscosidade devido ao aumento da temperatura, principalmente na base do reservatório, pela presença das canalizações. Além disso, o óleo com viscosidade de $300 \mathrm{cP}$, em toda ilustração, encontra-se azul devido à escala ser relativamente distante, porém no óleo de $10000 \mathrm{cP}$, observam-se altas viscosidades no topo do reservatório e baixas viscosidades na base devido ao aquecimento.

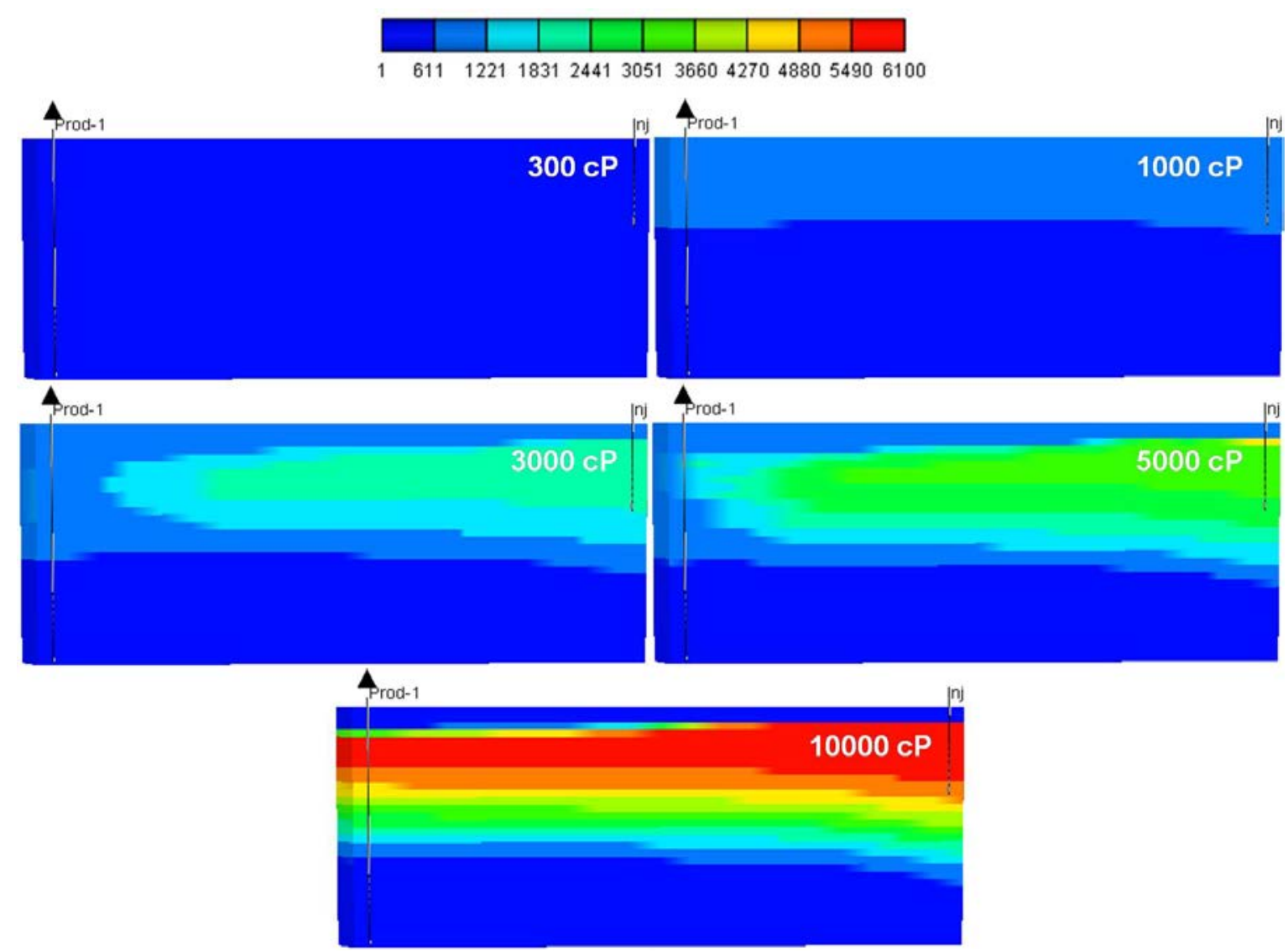

Figura 9 - Viscosidade do óleo (cP) $\left(3^{\circ}\right.$ ano de projeto)

Para esse estudo foram utilizados os três modelos de reservatório otimizados variando somente a viscosidade do óleo.

A Figura 10 mostra um comparativo das produções acumuladas de óleo para cada viscosidade. 
Observa-se um padrão para as curvas de viscosidade, sendo que quanto menor, maior a produção de óleo. As curvas de mesma cor representam mesmas viscosidades, as curvas com marcadores circulares representam a utilização do método AGI e as curvas sólidas apresentam a recuperação natural.

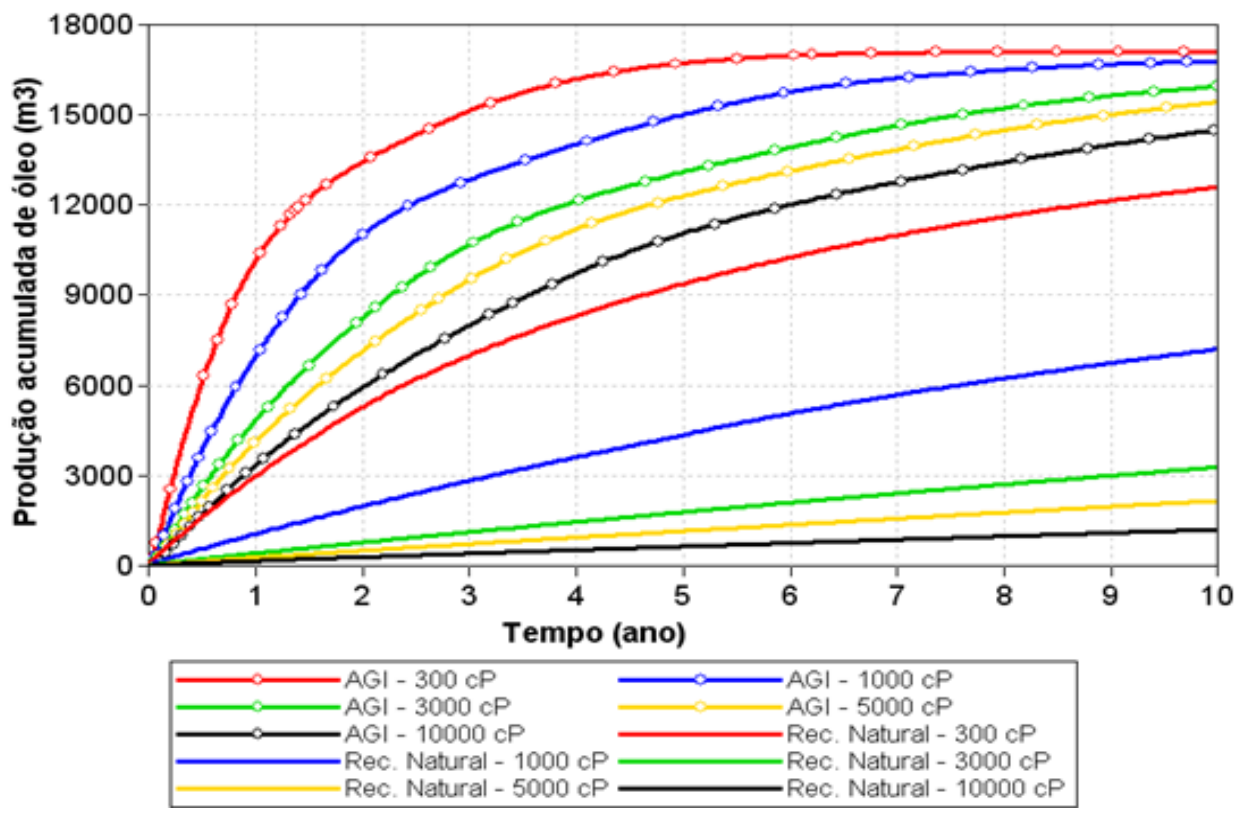

Figura 10 - Gráfico da Produção Acumulada versus Tempo. Comparativo de viscosidades no reservatório " $A$ "

Pode-se observar uma diferença significativa entre as recuperações primárias de modelos com diferentes viscosidades, essa diferença é bem menor quando são observados esses mesmos modelos com a utilização do processo AGI, sobretudo entre óleos de 300 e 10000 cP. Utilizando a recuperação natural obtém-se uma diferença de mais de $11000 \mathrm{~m}^{3}$ de óleo e utilizando o processo AGI essa diferença diminui para, aproximadamente, $2500 \mathrm{~m}^{3}$.

Na Figura 11, verificam-se altas vazões dos óleos menos pesados nos primeiros anos de projeto. Observa-se também que as vazões dos óleos mais densos são mais constantes e, por isso ao final do projeto atingem uma produção acumulada de óleo bem próxima às produções dos óleos mais leves, os picos de vazão são explicados pela chegada do banco de óleo ao poço produtor. 


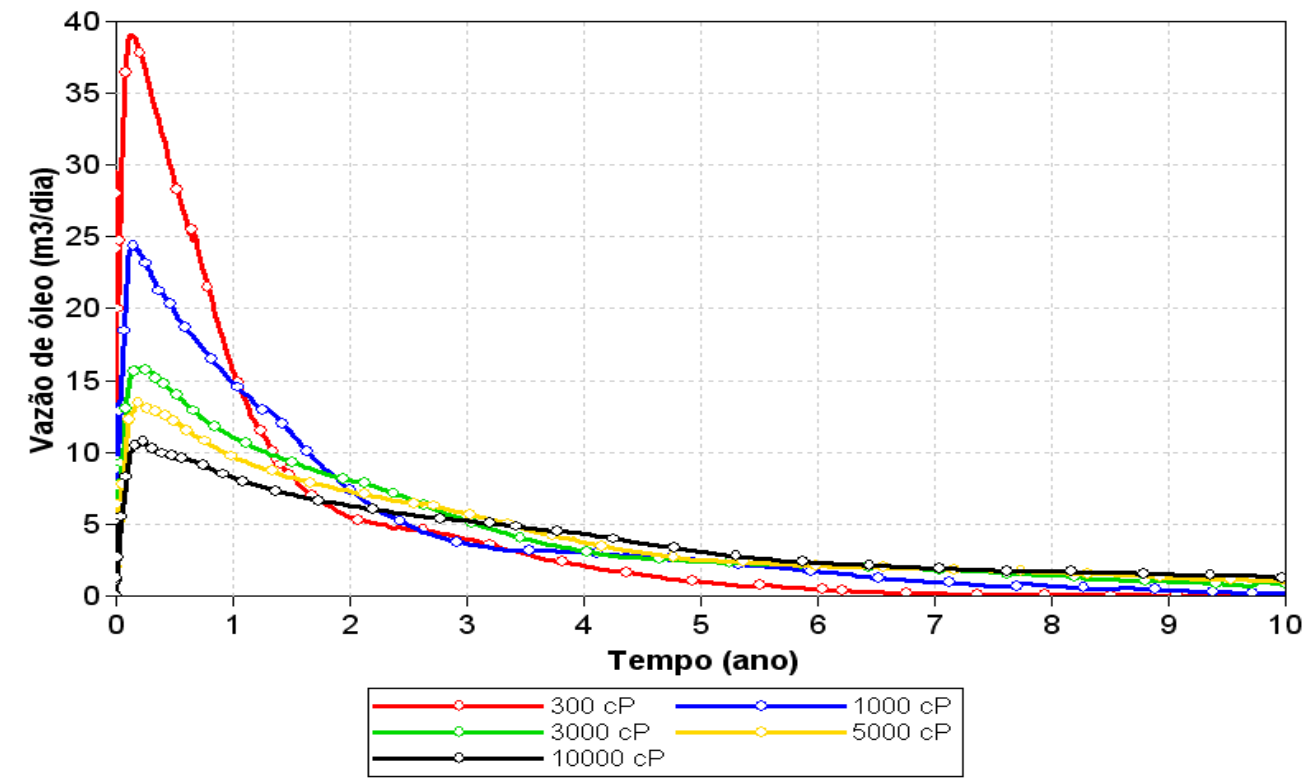

Figura 11 - Gráfico da Vazão de óleo versus Tempo. Comparativo de viscosidades no reservatório "A"

A Tabela 3 apresenta um comparativo do fator de recuperação final para as viscosidades estudadas no reservatório " $A$ ".

Tabela 3 - Comparativo de viscosidades para o reservatório "A" em 10 anos de projeto

\begin{tabular}{cccccc} 
Viscosidade (cP) & $\begin{array}{c}\text { NP } \\
\left(\mathbf{m}^{3}\right)\end{array}$ & $\begin{array}{c}\text { VOIP } \\
\left(\mathbf{m}^{3}\right)\end{array}$ & $\begin{array}{c}\text { FR (\%) } \\
\text { Rec. } \\
\text { Natural }\end{array}$ & $\begin{array}{c}\text { FR (\%) } \\
\text { AGI }\end{array}$ & $\begin{array}{c}\Delta \text { FR } \\
(\%)\end{array}$ \\
\hline 300 & 17118,2 & 21544 & 58,45 & 79,46 & 21,01 \\
\hline 1000 & 16779,1 & 21544 & 33,44 & 77,88 & 44,44 \\
\hline 3000 & 15952,7 & 21544 & 15,20 & 74,05 & 58,85 \\
\hline 5000 & 15417,8 & 21544 & 10,01 & 71,56 & 61,55 \\
\hline 10000 & 14502,2 & 21544 & 5,56 & 67,31 & 61,75 \\
\hline
\end{tabular}

- COMPARAÇÃO DE VISCOSIDADE PARA O RESERVATÓRIO “B”

A Figura 12 apresenta o gráfico das curvas de produção acumulada de óleo para variação das viscosidades no reservatório otimizado "B". As curvas de mesma cor representam mesmas viscosidades, as curvas com marcadores circulares representam a utilização do método AGI e as curvas sólidas apresentam a recuperação natural. A Figura 13 apresenta as curvas de vazão de óleo com a utilização do processo AGI. Observa-se um mesmo comportamento das curvas discutidas para o 
reservatório " $A$ ", sendo que nesse reservatório quanto mais pesado o óleo é apresentado um maior intervalo de tempo para chegada do banco de óleo no poço produtor.

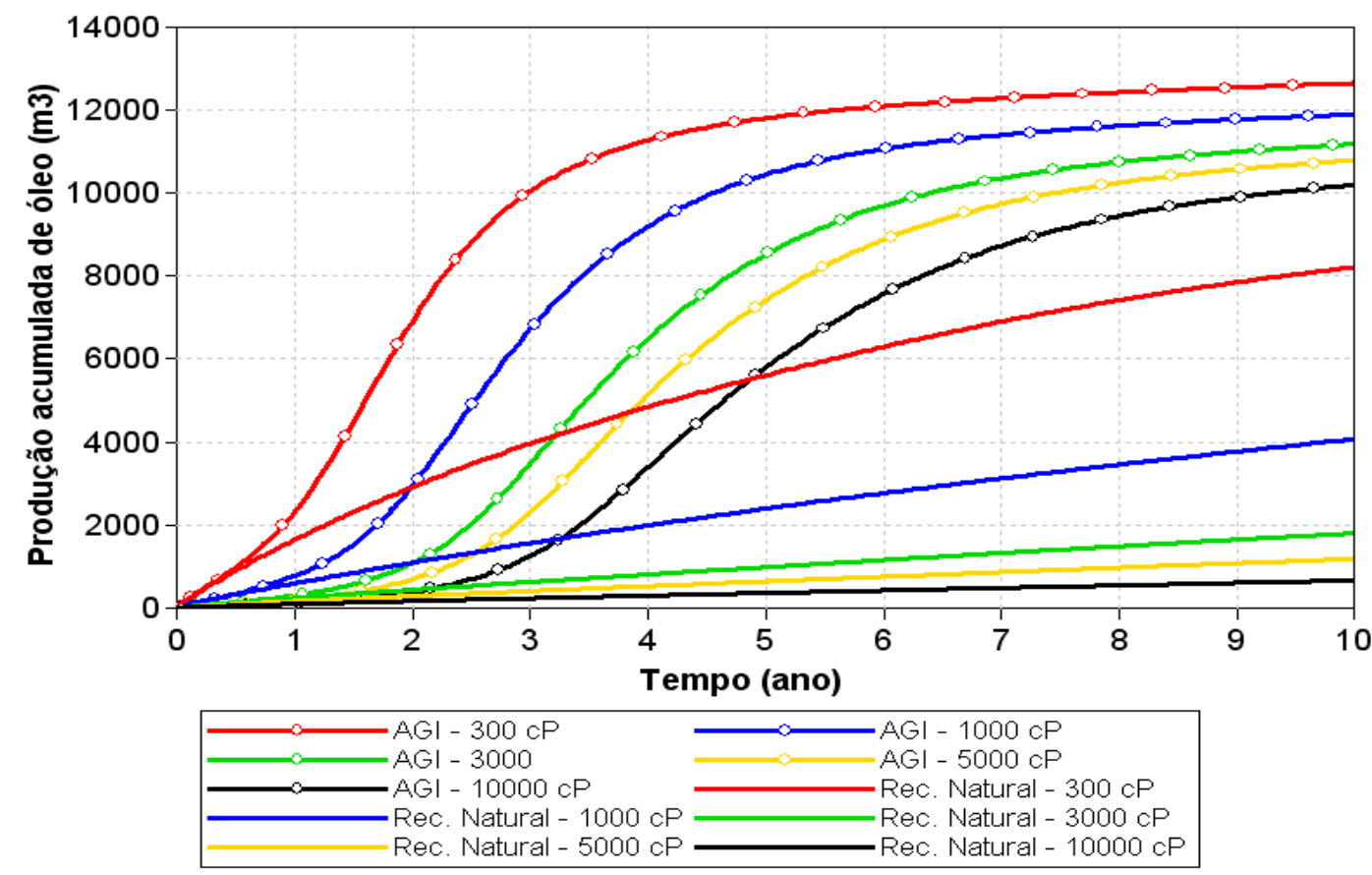

Figura 12 - Gráfico da Produção Acumulada versus Tempo. Comparativo de viscosidades no reservatório " $\mathrm{B}$ "

De forma análoga, observa-se uma diferença significativa entre as recuperações primárias de modelos com diferentes viscosidades, sendo essa diferença bem menor quando são observados esses mesmos modelos com a utilização do processo AGI, de forma semelhante, os picos de vazão ocorrem como resultado da chegada do banco de óleo ao poço produtor, contudo, nesse caso, as curvas são mais suaves devido às diferentes características do reservatório citadas anteriormente, tais como: capa de gás, permeabilidade e, principalmente, a profundidade, que reflete diretamente na pressão do reservatório. 


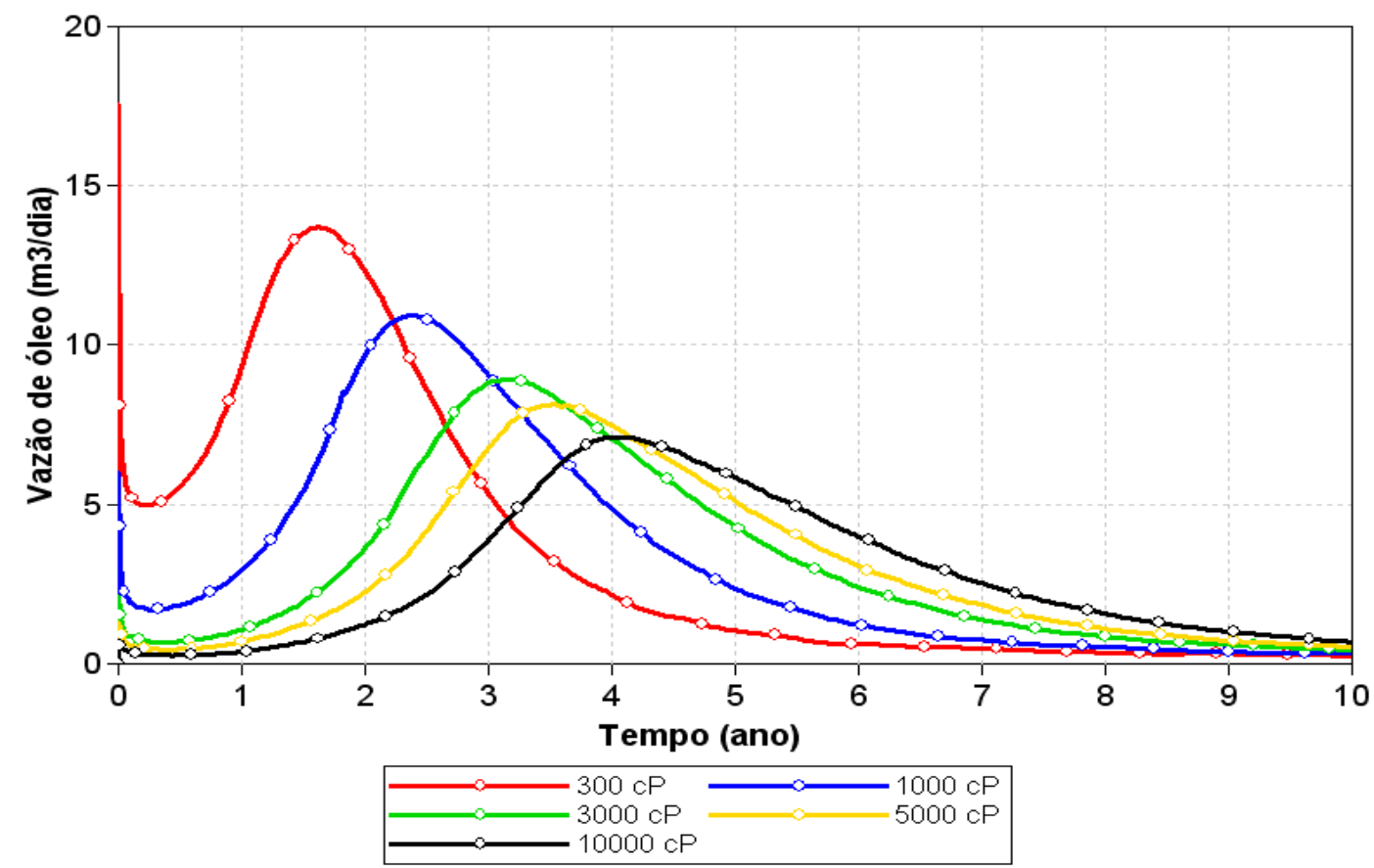

Figura 13 - Gráfico da Vazão de óleo versus Tempo. Comparativo de viscosidades no reservatório "B"

A Tabela 4 apresenta um comparativo do fator de recuperação final para as viscosidades estudadas no reservatório "B".

Tabela 4 - Comparativo de viscosidades para o reservatório “B” em 10 anos de projeto

\begin{tabular}{cccccc} 
Viscosidade (cP) & $\begin{array}{c}\text { NP } \\
\left(\mathbf{m}^{3}\right)\end{array}$ & $\begin{array}{c}\text { VOIP } \\
\left(\mathbf{m}^{3}\right)\end{array}$ & $\begin{array}{c}\text { FR (\%) } \\
\text { Rec. Natural }\end{array}$ & $\begin{array}{c}\text { FR (\%) } \\
\text { AGI }\end{array}$ & $\begin{array}{c}\Delta \text { FR } \\
(\%)\end{array}$ \\
\hline 300 & 12652,7 & 20107 & 40,87 & 62,93 & 22,06 \\
\hline 1000 & 11899,9 & 20107 & 20,23 & 59,18 & 38,95 \\
\hline 3000 & 11183,7 & 20107 & 8,95 & 55,62 & 46,67 \\
\hline 5000 & 10796,4 & 20107 & 5,89 & 53,69 & 47,80 \\
\hline 10000 & 10199,5 & 20107 & 3,30 & 50,73 & 47,43 \\
\hline
\end{tabular}


- COMPARAÇÃo dE VISCOSIDADE PARA O RESERVATÓRIO “C”

As curvas de viscosidade mantiveram um comportamento semelhante ao reservatório " $\mathrm{B}$ ". A Figura 14 e a Figura 15 apresentam as curvas de produção acumulada e vazão de óleo da variação de viscosidade no reservatório " $\mathrm{C}$ ". A Tabela 5 mostra um comparativo do fator de recuperação final para as viscosidades estudadas no reservatório " $\mathrm{C}$ ".

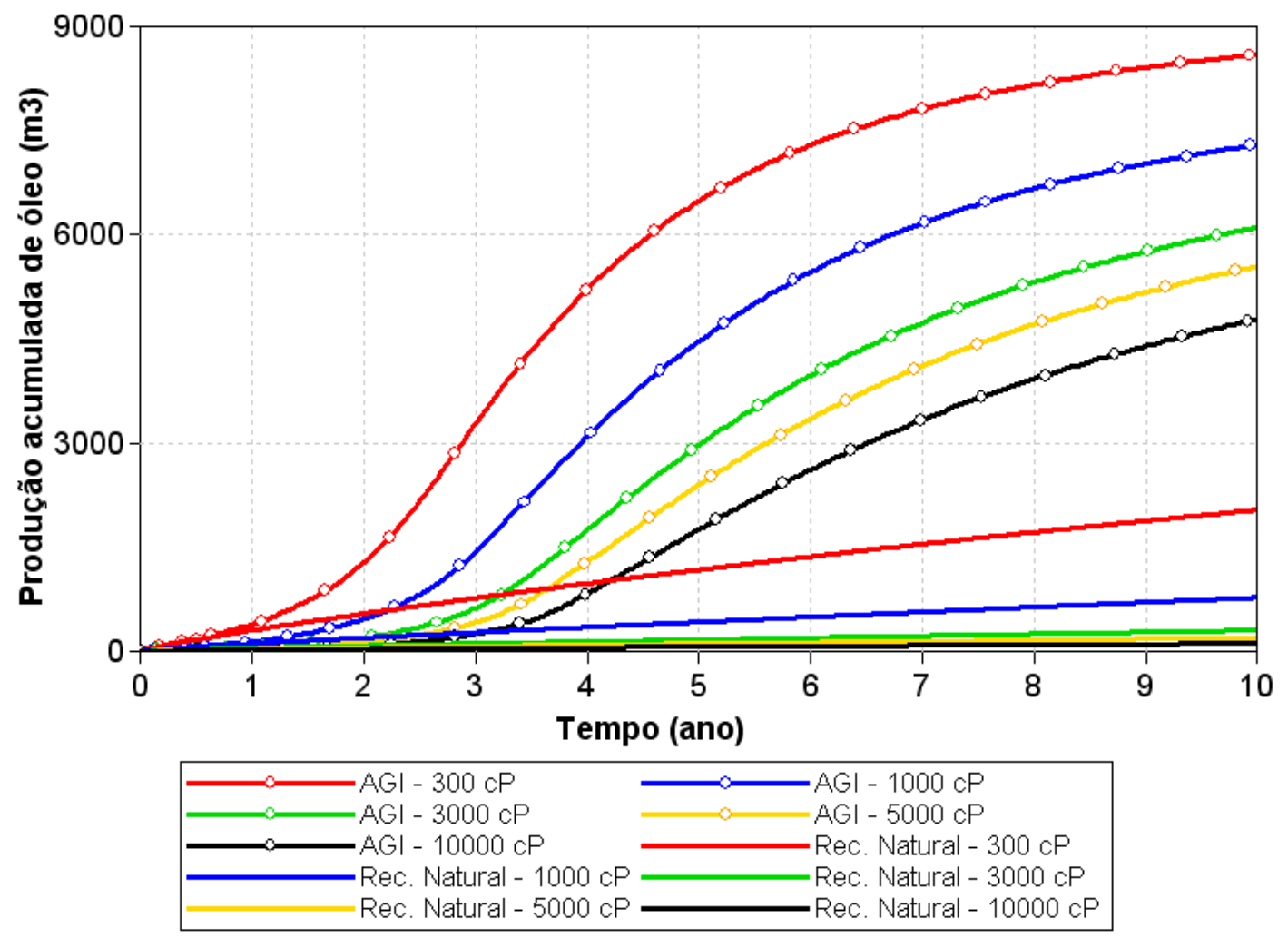

Figura 14 - Gráfico da Produção Acumulada versus Tempo. Comparativo de viscosidades no reservatório "C" 


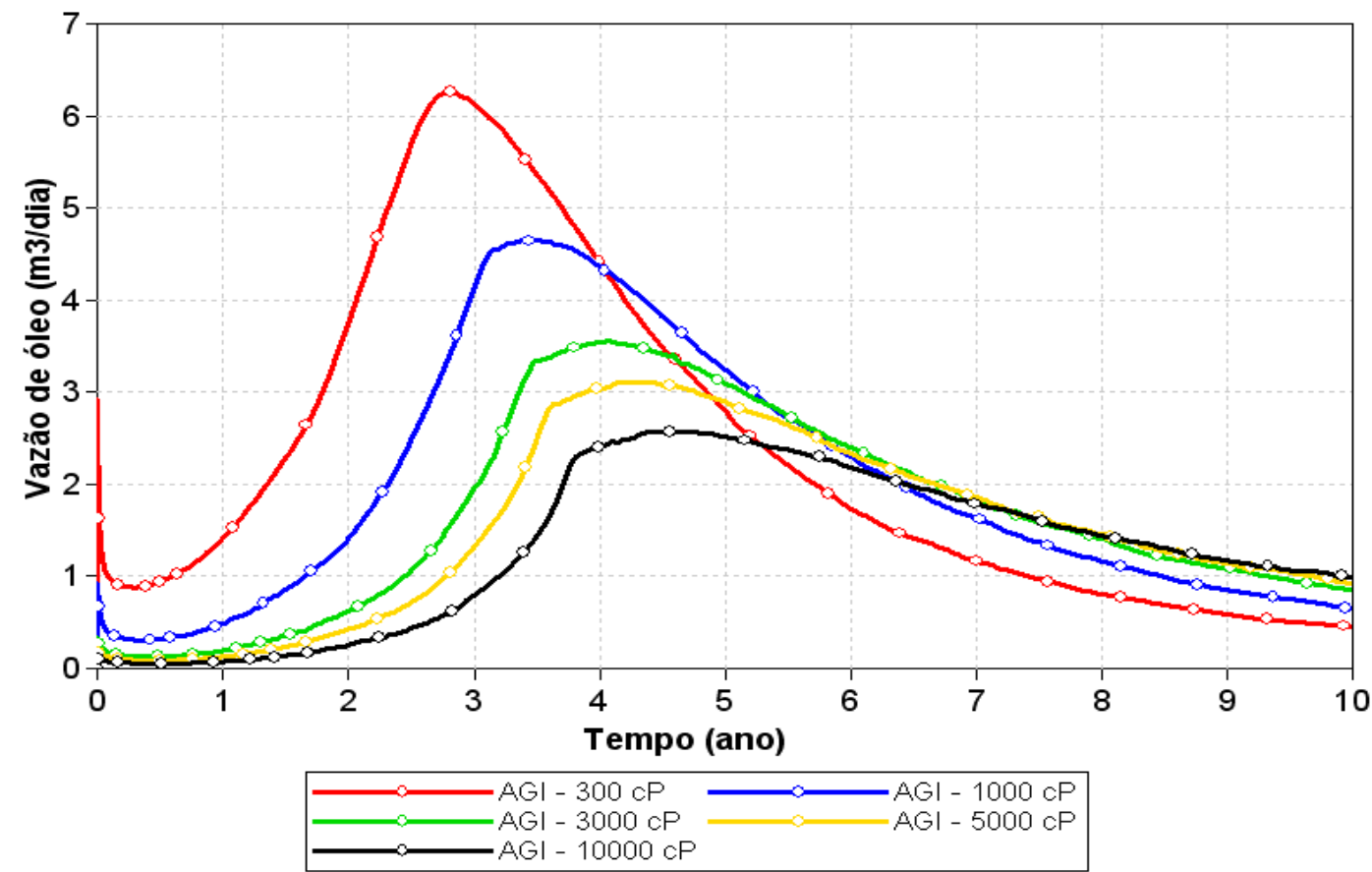

Figura 15 - Gráfico da Vazão de óleo versus Tempo. Comparativo de viscosidades no reservatório "C"

Analogamente, as curvas de mesma cor representam mesmas viscosidades, as curvas com marcadores circulares representam a utilização do método AGI e as curvas sólidas apresentam a recuperação natural.

Tabela 5 - Comparativo de viscosidades para o reservatório “ $\mathrm{C}$ " em 10 anos de projeto

\begin{tabular}{cccccc} 
Viscosidade (cP) & $\begin{array}{c}\text { NP } \\
\left(\mathbf{m}^{3}\right)\end{array}$ & $\begin{array}{c}\text { VOIP } \\
\left(\mathbf{m}^{3}\right)\end{array}$ & $\begin{array}{c}\text { FR (\%) } \\
\text { Rec. } \\
\text { Natural }\end{array}$ & $\begin{array}{c}\text { FR (\%) } \\
\text { AGI }\end{array}$ & $\begin{array}{c}\Delta \text { FR } \\
(\%)\end{array}$ \\
\hline 300 & 8595,7 & 20093 & 10,11 & 42,78 & 32,67 \\
\hline 1000 & 7295,43 & 20093 & 3,82 & 36,31 & 32,49 \\
\hline 3000 & 6103,73 & 20093 & 1,49 & 30,38 & 28,89 \\
\hline 5000 & 5541,82 & 20093 & 0,96 & 27,58 & 26,62 \\
\hline 10000 & 4781,76 & 20093 & 0,54 & 23,80 & 23,26 \\
\hline
\end{tabular}

A Figura 16 apresenta uma comparação entre as diferenças da recuperação percentual com aquecimento e recuperação natural, para cada umas das viscosidades estudadas. 


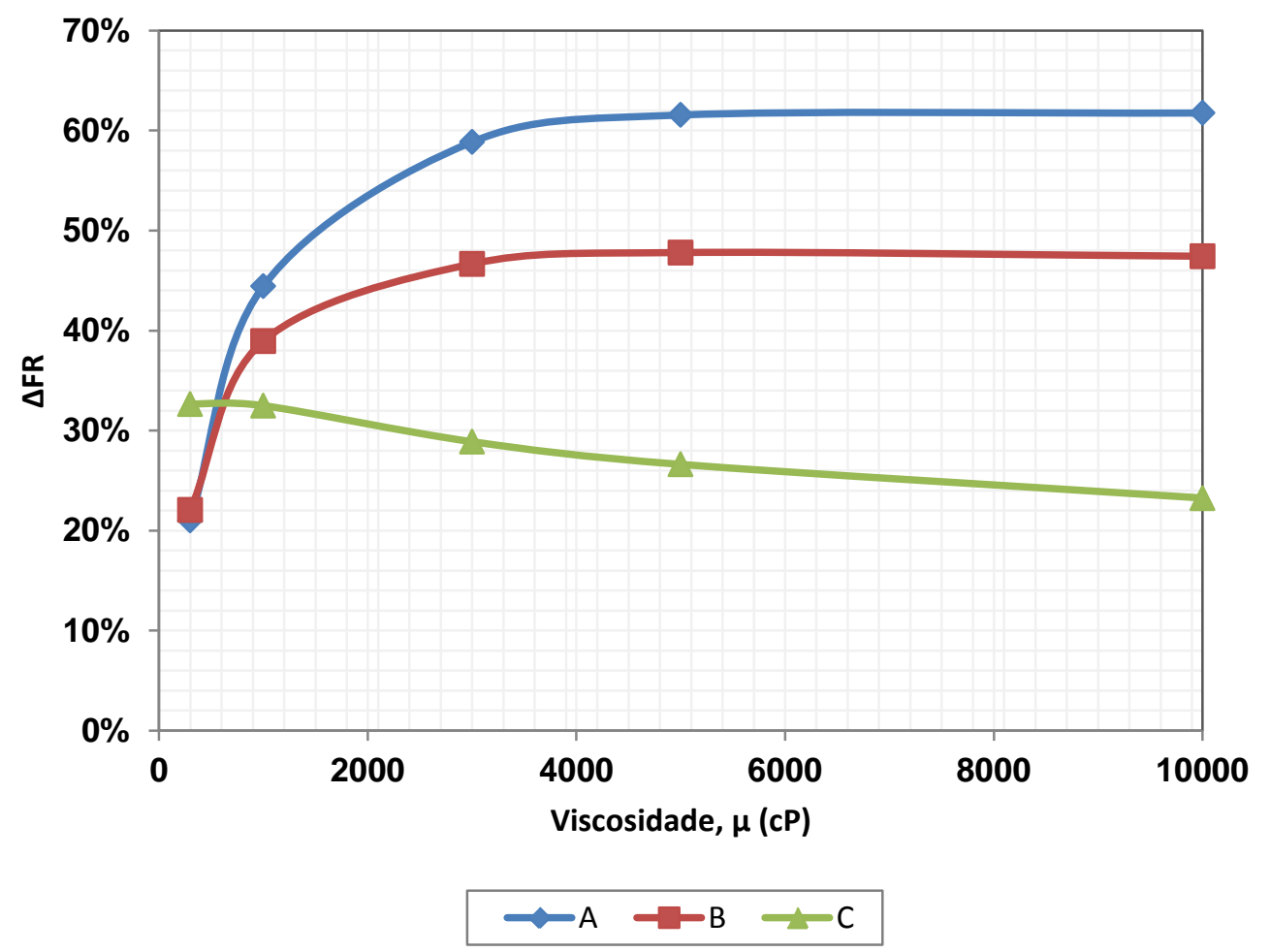

Figura 16 - Comparação entre reservatórios e viscosidades

Observa-se um comportamento semelhante entre os reservatórios " $A$ " e "B". Nesses reservatórios quanto maior a viscosidade do óleo maior a diferença entre a recuperação primaria e a recuperação com o Aquecimento Geral Indireto. Isso ocorre, aproximadamente, até a viscosidade de 3000 cP, após essa etapa não se observa grande alteração nas diferenças de recuperação.

Para o reservatório " $\mathrm{C}$ ", ocorre exatamente o inverso, ou seja, quanto menor a viscosidade do óleo menor a diferença entre a recuperação natural e a recuperação com a utilização do Aquecimento Geral Indireto. Vale salientar que nesse reservatório não ocorre grande mudança nas diferenças de recuperação de óleos mais leves e mais pesados.

\section{CONCLUSÕES}

- Quanto menor for a viscosidade do óleo, mais elevada será sua produção, todavia óleos muitos viscosos podem ter esse parâmetro reduzido através de aquecimento.

- O óleo disposto mais próximo das canalizações sofre maior redução na viscosidade.

- O AGI produz aumento significativo em relação às recuperações primárias, sobretudo entre óleos de 5000 e 10000 cP. 
- As vazões dos óleos mais pesados são mais constantes.

- Em um reservatório com condições semelhantes às descritas, quanto maior a viscosidade do óleo, maior a diferença entre a recuperação primária e a recuperação com o AGI. Após 3000 cP não se observam grandes alterações.

\section{REFERÊNCIAS BIBLIOGRÁFICAS}

1. ALBOUdWAREJ, H.; FELIX, J.; TAYLOR, S. Highlighting heavy oil, Oilfield Review. 34-53 p., Junho, 2006, disponível em: www.slb.com, acessado em agosto de 2007.

2. BARILLAS, J. L. M. Estudo do processo de drenagem gravitacional de óleo com injeção contínua de vapor em poços horizontais. Dissertação (Mestrado em Engenharia Química) - Universidade Federal do Rio Grande do Norte, 163 p., Natal, 2005.

3. DUNN-NORMAN, S.; GUPTA, A.; SUMMERS, D. A.; KOEDERITZ, L. F.; NUMBERE, D. T. Recovery methods for heavy oil in ultra-shallow reservoirs. In: SPE Western Regional/AAPG Pacific Section Joint Meeting, SPE 76710, p. 1-4. Alaska, USA, 20-22, Maio, 2002.

4. DUTRA JR, T. V. Desenvolvimento de um simulador numérico para a injeção cíclica de vapor. Dissertação (Mestrado em Engenharia de Petróleo) - Universidade Federal de Ouro Preto, Abril, 1987.

5. MEDEIROS, E. J. R. de. Estudo do aquecimento geral indireto como método de recuperação em reservatórios rasos de óleos pesados. Dissertação (Mestrado em Ciência e Engenharia de Petróleo) - Universidade Federal do Rio Grande do Norte, 197 p., Natal, 2008.

6. MOREIRA, R. D. R.; TREVISAN, O. V. Estratégia de injeção de vapor em poço horizontal único. In: PDPETRO 4, Campinas, p. 1-10, 21-24 Outubro, 2007

7. MOTHÉ, C. G.; SILVA JR, C. Petróleo pesado e ultrapesado - reservas e produção mundial. Revista TN Petróleo, V 57, p. 76-80, 2008, disponível em: www.tnpetroleo.com.br, acessado em fevereiro 2008.

8. NZEKWU B. I.; PELENSKY P. J. Single horizontal wellbore gravity drainage assisted steam flooding process. United States Patent 5626193, 6, Maio, 1997.

9. OSTERLOH, W.T.; JONES, J. Novel thermal process of recovery of extremely shallow heavy oil. SPE 83733, Bakersfield, California, EUA, p. 127-134, Março, 2003.

10. OSTERLOH, W. T.; JONES, J. Process for recovery of extremely shallow heavy oil. In: SPE Western Regional Meeting, SPE 68809, Bakersfield, California, EUA, Março, 2001.

11. SCHIOZER, D. J. Texto auxiliar para simulação numérica de reservatórios. UNICAMP. 75 p., disponível em: www.dep.fem.unicamp.br, acessado em novembro 2007.

12. STARS User's Guide. Advanced process and thermal reservoir simulator, Computer Modelling Group Ltd, 2007. 